Original Research Paper

\title{
Numerical Analysis of Lattice Structures for Skin Layer in Camber Morphing Wing
}

\author{
${ }^{2}$ Bashir Alsaidi, ${ }^{1}$ Woong Yeol Joe and ${ }^{2}$ Muhammad Akbar \\ ${ }^{1}$ KBJ Innovation Co., Nashville, USA \\ ${ }^{2}$ Department of Mechanical and Manufacturing Engineering, Tennessee State University, Nashville, USA
}

Article history

Received: 14-05-2019

Revised: 06-07-2019

Accepted: 13-07-2019

Corresponding Author:

Woong Yeol Joe,

KBJ Innovation,

Nashville, USA

Email: joewy77@gmail.com

\begin{abstract}
Unlike conventional fixed wings and their static skin structure considering only expected aerodynamic loadings while filight, design strategies of skin structure for morphing wings require careful consideration of structural loading from shape changes and aerodynamics and their coupled effects in flight. Many morphing wings often overlook skin material and structure for the wing design. In addition to that, many works in the design of skins for morphing wings typically use smart materials, consider only geometric or static analysis but not dynamic deformation and strengths, or suggest a material condition and its properties that satisfy required structural and aerodynamic conditions. This work is focused on numerical analysis of structural and aerodynamic stress and strain of various lattice structures that will suggest desired design criteria of skin in camber morphing wings in the future. As a result, this paper shows numerical analysis of various lattice structures in accordance with camber moprhing and their potential effectiveness for skin of morphing wings.
\end{abstract}

Keywords: Wing Morphing, Lattice, Flexible Skin, Camber Morphing, Numerical Analysis

\section{Introduction}

Skin morphing can be imagined as an aerodynamic fairing to cover an underlying morphing structure. Skin is the most vulnerable and sensitive structure to aerodynamics in flight. Conventional fixed wing aircraft normally uses aluminum skin in their wings of 1-2 mm thickness to endure aerodynamic effects including gust and sometimes unexpected loadings. Furthermore, skin structure or material selection for skin simply plays a role of wrapper around the wing to be robust enough to minimally deform (another 1-2 mm) according to external loadings. However, when morphing or active geometry/shape changes in wings are considered, not only structural aspects of morphing and their mechanism newly appear but also the design of skin and material becomes an important problem accordingly. For example, in chord extension morphing, the skin around the wing is not only desired to be flexible in chord direction but also required to maintain out-ofplane or span directional loadings, which makes this design problem challenging.
Wing morphing technology is found to be one of the potential techniques that can improve aerodynamics Lift/drag ratio of airfoil wing drastically. Recently, many researchers intended towards the study of smart materials and their aerodynamics applications to investigate shape morphing (Akbar et al., 2018; Jenett et al., 2017; Bilgen et al., 2007; Vigliotti and Pasini, 2015; Santer and Pellegrino, 2019; Oliviu et al., 2016). Manipulating and geometrical wing changing help in optimizing flight conditions and reducing fuel consumption of aircrafts. Among various types of morphing in aircraft, the scope of study in this paper falls into airfoil morphing and camber change in airfoil as shown in Fig. 1. Camber morphing in this study employs seamless and conformal techniques (Ajaj et al., 2014; Marques et al., 2009; Woods and Friswell, 2013; Woods and Friswell, 2014) as shown in Fig. 2. Among many structure design concepts and material selection, authors consider the usage of lattice structure of a material, ABS for the skin of camber morphing wing. The lattice structure of a material is designable and could be parameterized in its unit cell structure or structure as a whole to adjust its mechanical behaviors such as strength, 
Young's modulus, Poisson's ratio, stress/strain and so on (Mestrinho et al., 2011; La et al., 2018; Alsulami et al., 2017). This study aims to (1) compare 3D real wing model with 2D lattice model for equivalency studies for design and modification purposes and (2) analyze stress/strain of different lattice structures for design criteria process.

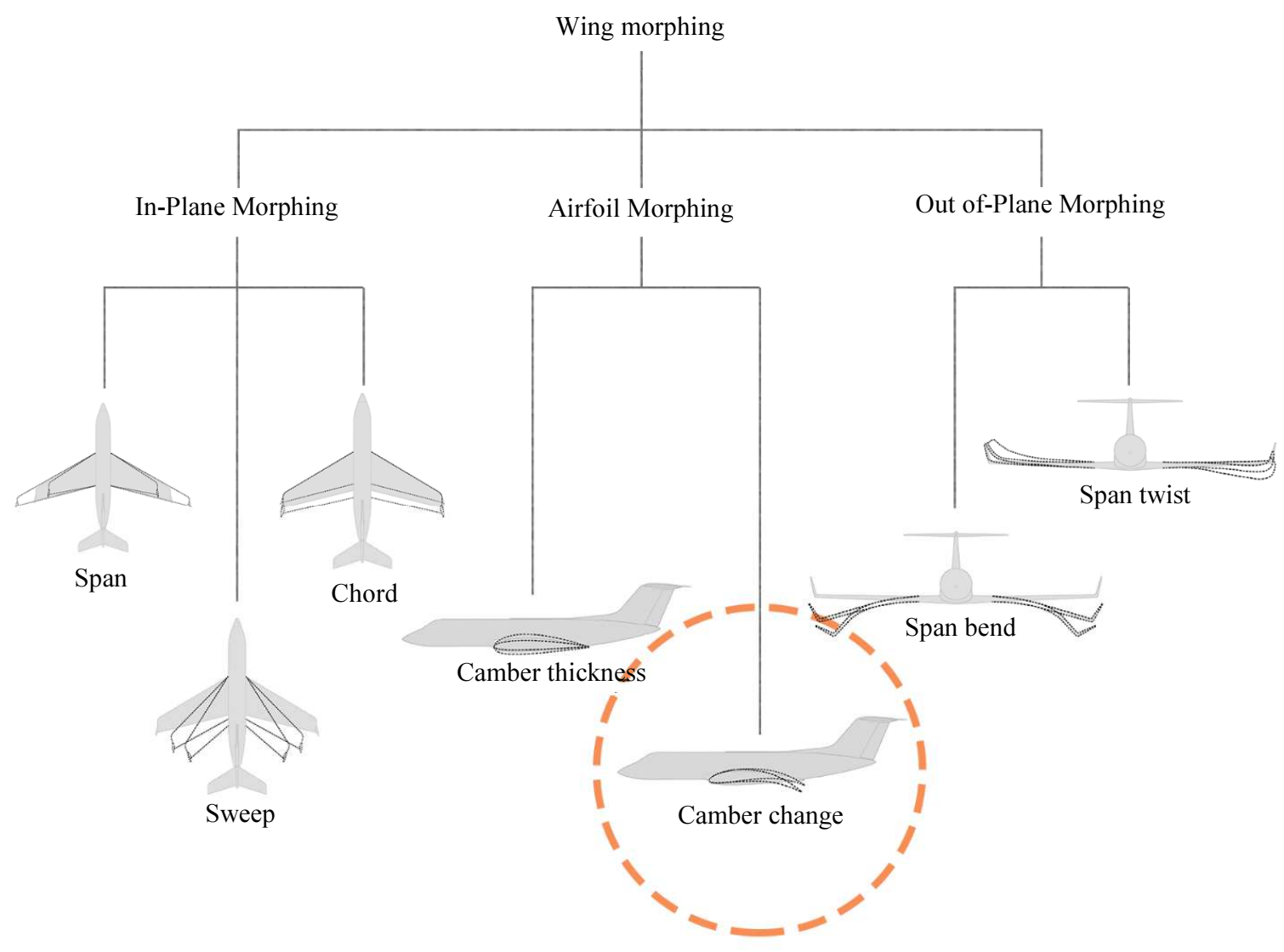

Fig. 1: Diagram of categories of wing morphing with camber change morphing highlighted

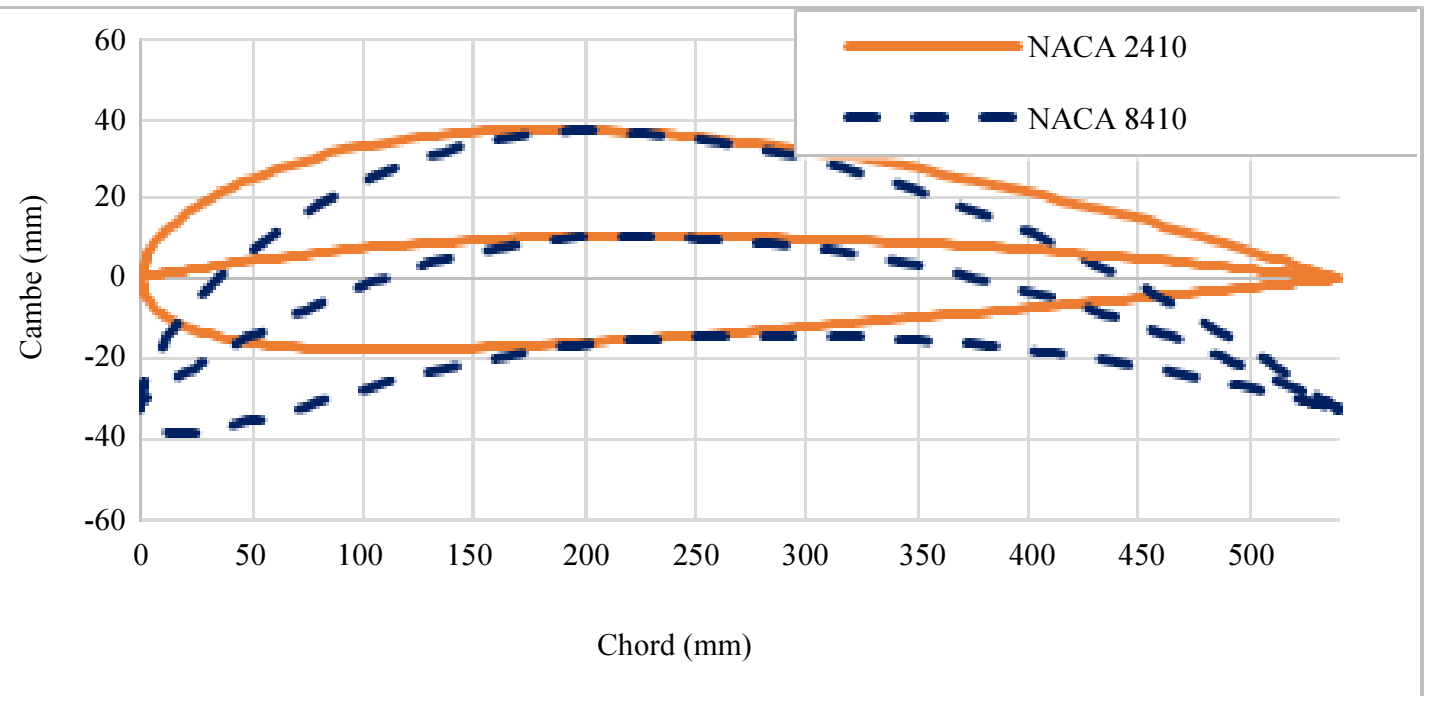

Fig. 2: Total 6\% camber morphing 2D profile: From NACA2410 (2\%) to NACA8410 (8\%) 


\section{Aircraft Model}

A retired UAV model, RQ-7a, is selected for this study shown in Fig. 3(a). Dimensions of the wings are 1.828 meters in span and 0.54 meters in chord direction. The theme of this paper, computational model of skin structure for morphing aircraft, is based on this RQ-7a model, however; we now assume that wings morph their camber rates up to $6 \%$ with base airfoil NACA 2410 as shown in Fig. 2. For the skin design purpose, skin requirement in conventional fixed wing aircraft is 4.6 $\mathrm{kg} / \mathrm{m}^{2}$ with aluminum sheet that is stiff enough in the out-of-plane direction. The spar is located at $40 \%$ from leading edge (i.e., $216 \mathrm{~mm}$ ). These specifications are summarized in Table 1.

In our computational model of the wing, evenly spaced ribs as shown in Fig. $3 \mathrm{~b}$ are positioned and hollow in-between. Each rib can morph up to $6 \%$ to realize seamless and conformal camber morphing as expected. The number of actuators depends on the size of wing in spar direction and the percentage of camber change. Furthermore, the total length of wing also has influence on the number of actuators as well as the outof-plane deformation. The boundary conditions of our computational model will be discussed in next section.

Table 1: Detail Specifications of RQ-7a, Aircraft Model for Study

\begin{tabular}{llll}
\hline Wing span & $1.828 \mathrm{~m}$ & Wing chord & $0.54 \mathrm{~m}$ \\
\hline Wing Skin thickness & $4.6 \mathrm{~kg} / \mathrm{m}^{2}$ & Spar location & $40 \%$ from leading edge \\
Morphing range & Fixed wing & Takeoff weight & $1452 \mathrm{~N}$ \\
Empty weight & $823.8 \mathrm{~N}$ & Gross weight & $1646.8 \mathrm{~N}$ \\
\hline
\end{tabular}
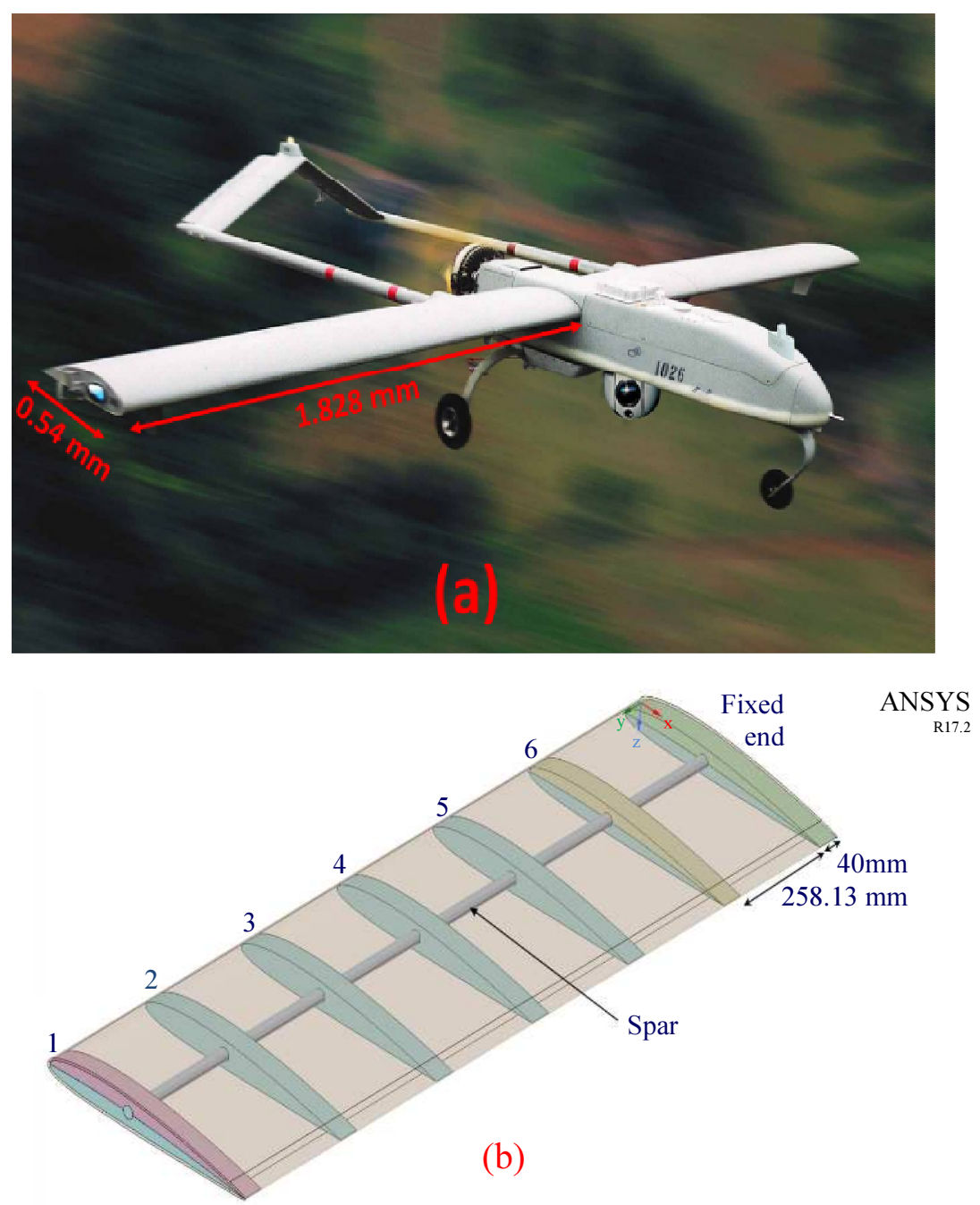

Fig. 3: (a) Selected UAV model RQ-7a and (b) computational model of camber morphing wing: 1-6 shows the position of morphable ribs and the fixed spar location 


\section{Wing Skin Model and Boundary Condition}

Skin morphing, as it is known, is the continuous shape changing. In order to achieve such continuity change, we need initially to create the internal structure that would be capable to support the external skin layer. Therefore, the original structure is created at first by forming a wing of NACA 2410 profile. Then, the wing structure wrapped by $5 \mathrm{~mm}$ seamless skin composite layer. The material of designed wing and skin layer are required to be flexible enough such that it would comply with any deformation that would undergo without fracture, i.e. Polyethylene or ABS composite. The selected wing dimensions of prototype are 1.828 meter span by 0.54 meter chord. The spar located at $40 \%$ from leading edge (i.e., $216 \mathrm{~mm}$ ). Spar is the only fixed part of the wing and meant to support the structure of wing.

The objective of this design is to achieve $6 \%$ camber change of four digits series profile of NACA8410 from NACA2410. Therefore, after several design and analyzing, the optimal camber profile could be achieved as shown in Fig. 4.

As mentioned before, the prototype has designed for fixed wing, hence the wing is fixed at the fuselage side and free at the other end. Therefore, the camber of model is capable to deform to its maximum value (NACA8410 profile) at the free end while it maintains undeformed (NACA2410) at the fixed side. The linearity of displacement is to ensure that the wing retains undeformed in the fixed side (NACA2410) while it achieves the maximum deformation (NACA8410) at the free side. The optimal NACA8410 chamber profile attained found to be when we applied $28 \mathrm{~mm}$ in the bottom edge leading side and $18 \mathrm{~mm}$ in the bottom edge trailing side in the free end of wing.

Camber morphing is a continuous shape change of the outer shell of a wing under geometrical deformations. In order to achieve such continuous and seamless changes, we need to create an internal frame structure that would be capable to support the external skin layer. ANSYS structural modeler (ANSYS Fluent Theory Guide, 2016) was used in this study. The initial structure is created by forming a wing of NACA 2410 profile which means the wing is free of stresses. These boundary conditions and their perspective coordinates are tabulated in Table 2.

Total $6 \%$ morphing does not necessarily mean the camber needs to morph to only NACA8410. In other words, camber can morph any rate from 2410 to 8410 . In this paper, we consider the maximum morphing percentage \%6, NACA8410 respectively assuming stress and strain relation with morphing percentage is linear and could be extrapolated. Furthermore, if it is linear, we can consider only rib to rib section not the whole wing as shown in Fig. 5.

Table 2: Wing's boundary conditions and their perspective coordinates

\begin{tabular}{llll}
\hline Parts & X coordinate $(\mathrm{mm})$ & Y coordinate $(\mathrm{mm})$ & $\mathrm{Z}$ coordinate $(\mathrm{mm})$ \\
\hline Actuator 1 (free end) & $0-540$ & $1788.78-1828.78$ & 0 \\
Actuator 2 & $0-540$ & $1490.65-153.65$ & 0 \\
Actuator 3 & $0-540$ & $1192.52-1232.52$ & 0 \\
Actuator 4 & $0-540$ & $894.39-934.39$ & 0 \\
Actuator 5 & $0-540$ & $596.26-636.26$ & 0 \\
Actuator 6 & $0-540$ & $298.13-338.13$ & 0 \\
Fuselage (fixed end) & $0-540$ & $0-40$ & 0 \\
Spar & 216 & $0-1828.78$ & 0 \\
\hline
\end{tabular}

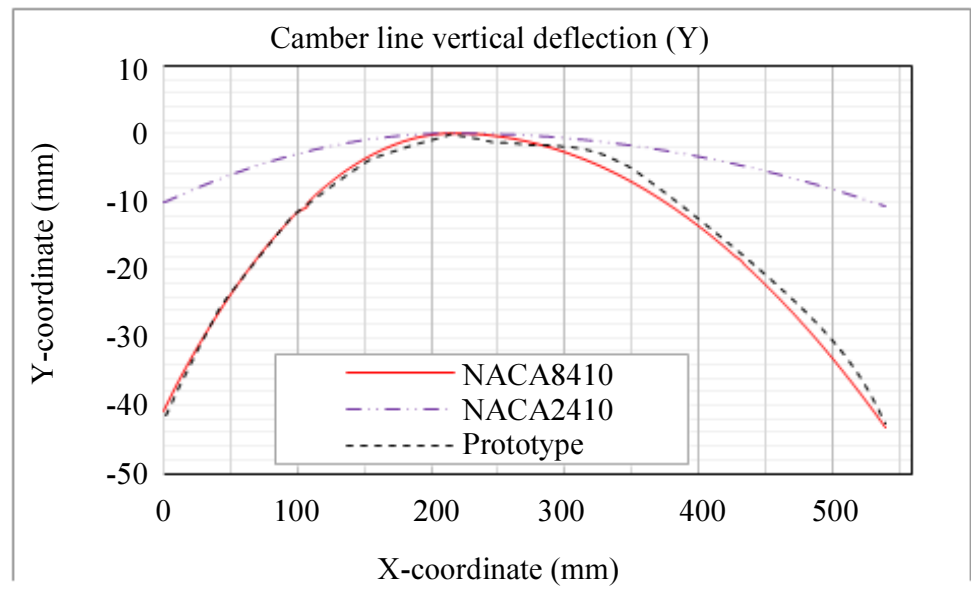

Fig. 4: Standard NACA Profiles comparing with prototype camber profile 


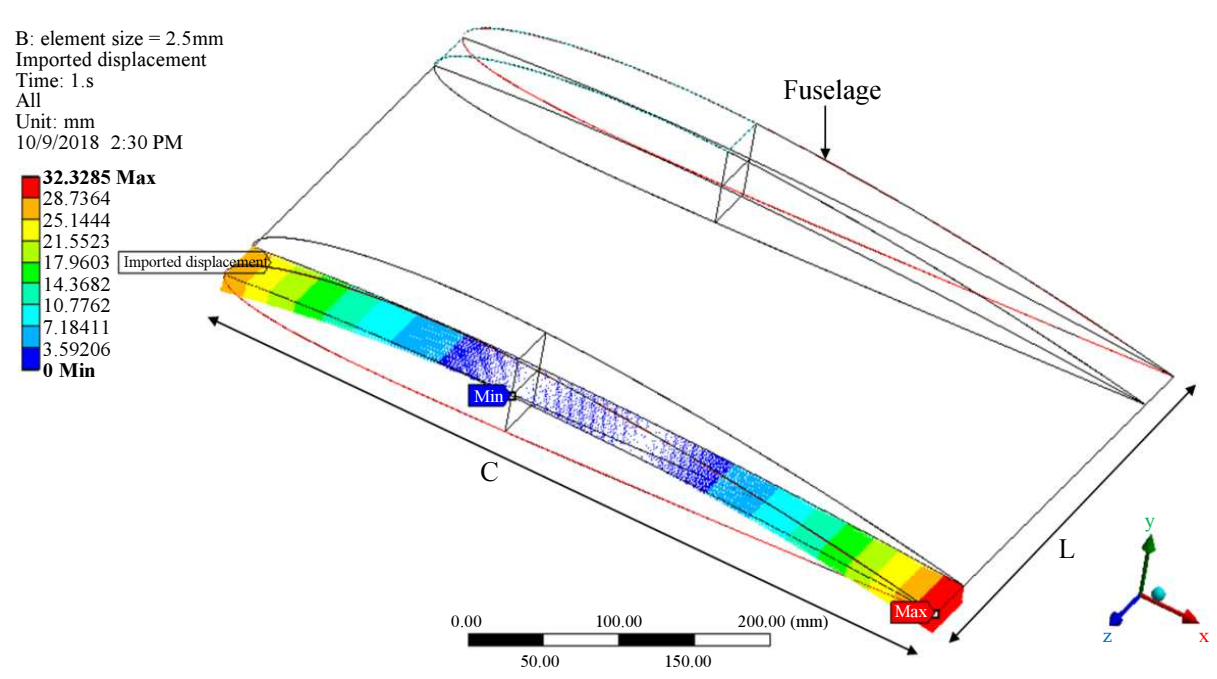

Fig. 5: Real wing model with some important design parameters

\section{Structural Analysis}

In this section, we focus on understanding the structural stress/strain of 3D camber morphing wing. In order to design advanced skin structure that is flexible to wing span/chord directions while rigid to out-of-plane or vertical direction, first we must be able to measure corresponding stress/strain in various camber morphing rates. This section is composed two major parts: (1) modeling bulk material 3D structure wrapped around the wing stress/strain in, computing corresponding data, (2) verifying 2D structured (plate) data compared to previously acquired $3 \mathrm{D}$ data in step 1 for $2 \mathrm{D}$ lattice structure design purposes.

\section{D ABS Bulk Material Structure}

As shown in Fig. 5, ABS shell model has been applied to 3D morphable wing. One side is fixed with NACA2410 pretending attached to fuselage and the other side morphed to NACA8410 resulted to total $6 \%$ camber change. As we expect, multi-axial stress/strain are computed including normal $\mathrm{x}, \mathrm{y}, \mathrm{z}$ directions, shear stresses in 3 planes: $x-y, x-z, y-z$ respectively and equivalent stress/strain as shown in Fig. 6-7.

Some of the mechanical properties related to wing morphing have been tested for different input of NACA profiles, i.e., $1 \%$ to $6 \%$ camber change. The results are shown in Fig. 6-7. However, if the wing has to morph to the maximum profile at $6 \%$ camber change then, the generated shear stress for ABS bulk material would be around $24.6 \mathrm{MPa}$ while the shear strain is about 0.066 . When camber rate changes from 2 to $6 \%$, shear stress changes from 7 to $24 \mathrm{MPa}$, normal

stress in $\mathrm{x}$-direction from 18 to $97 \mathrm{MPa}$, normal stress in $\mathrm{z}$-direction from 18 to $102 \mathrm{MPa}$ respectively. Furthermore, when camber rate changes from 2 to $6 \%$, normal directional strains in both $\mathrm{x}$ and $\mathrm{z}$ are from 0.01 to aroud 0.07 . Fig. $6 \mathrm{c}$ shows the combined graph of strain vs. stress. It is of interest that stress and strain are linear to camber change rate and normal stress/strain in $\mathrm{x}$ and $\mathrm{z}$ are very similar to each other.

\section{D ABS Bulk Material Structure}

The 2D-plate model shown in Fig. $3 \mathrm{~b}$ has been simulated to resemble the real wing model. Same material type and properties assumed for both models which is ABS material. Thus, dimensions of $C$ and $L$ parameters are $540 \mathrm{~mm}$ and $260 \mathrm{~mm}$ respectfully. The boundary conditions of this 2D model are; fixed fuselage, free along camber line of $\mathrm{C}$ parameter, an inplane variable input displacement applied along parameter $L$ to resemble the different NACA profiles shown in Fig. 3a, the out-of-plane deformation in Ydirection left free in this case. Note that the thickness of both models of real wing and 2D-plate are the same which is $5 \mathrm{~mm}$. Also, shell model assumed for this FEA study just like real wing model.

The mechanical properties related to wing morphing in 2D perspective has been tested for different inputs of linear profiles where the maximum input for each test meant to resemble the maximum deformation of each of NACA profiles, i.e., $1 \%$ to $6 \%$ camber change. The results are shown in Fig. 4. These results clearly indicate that, if the wing has to morph to the maximum profile at $6 \%$ camber change then, the generated shear stress for ABS bulk material would be around $32.5 \mathrm{MPa}$ while the shear strain is about 0.088 .

Relation Between 3D wing Model and 2D Plate Wing Model

What is important here is that we need to achieve to suitable relation of some of the mechanical properties for the two different cases, i.e., real wing model versus 2D-plate model. In order to define these relationships, the elastic region which is represented by the fixed rate 
of stress to strain has been calculated and matched up for both models. Fig. 8a represents the stress/strain curve which is clearly shows good agreement of the elastic limits for both models regarding the in-plane shear stress property.

From the achieved results, it is noted that the shear stress/strain between $2 \mathrm{D}$ and 3D model has no significant difference. Also, it could be concluded that shear stress/strain could be used as a good property indicator when designing lattice structure for $3 \mathrm{D}$ wing model. However; any structure considering design stage must consider design factors such as safety factors, strength of the material and other criteria. Here we found out and verified how stress/strain in actual 3D models are represented in 2D models and what relations exist. 2D models are necessary in design optimization, modification and innovation stage for design while 3D computational models require enormous computational efforts in analysis which makes almost impossible to simulate parameter studies of new structure designs.

While Fig. 8a show the range of strain from 0 to 0.1 in shear direction, any structure of a material has elastic and plastic deformation regions which could be critical in design stage considering safety factors. Therefore, authors consider extending shear strain until appearance of plastic deformation as shown in Fig. 8b. S-S (strain vs. stress) curve shows deformation starts 0.035 strain and corresponding stress is around $10 \mathrm{MPa}$ of 2D ABS bulk material model respectively.

Next section, we investigate more how a lattice structure behaves under given rages of stress/strain compared with 3D model data that suggest eventually how to optimize and modify $2 \mathrm{D}$ lattice structure to meet required mechanical properties.

\section{Lattice Structures}

In this section shown in Fig. 8-13, we demonstrate behaviors of various lattice structures in their stress/strain. This is an important indicator of selecting most appropriate lattice structure as base for future optimization. Total 5 lattice structure were analyzed for stress/strain. There are specific reasons for selection these structures: (1) previous history of studies as morphing wing skins; (2) zero or low Poisson's ratio; (3) low in-plane stiffness and high out-of-plane stiffness; (4) sufficient flexibility for morphing performance. All structures modeled with same relative mass density of about 0.38 .

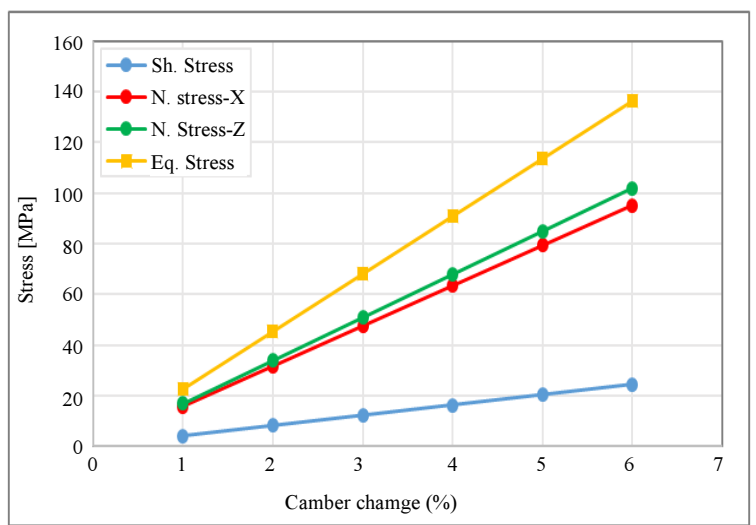

(a)

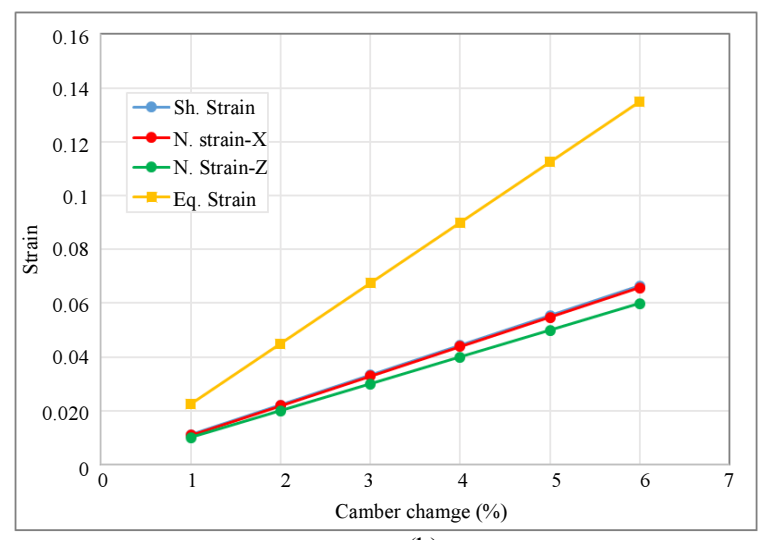

(b)

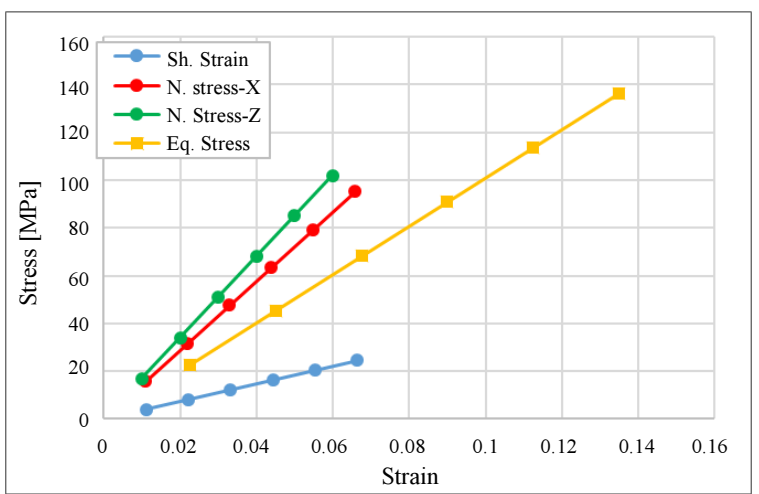

(c)

Fig. 6: (a) camber rate vs. stress (b) camber rate vs. strain and (c) strain vs. stress 


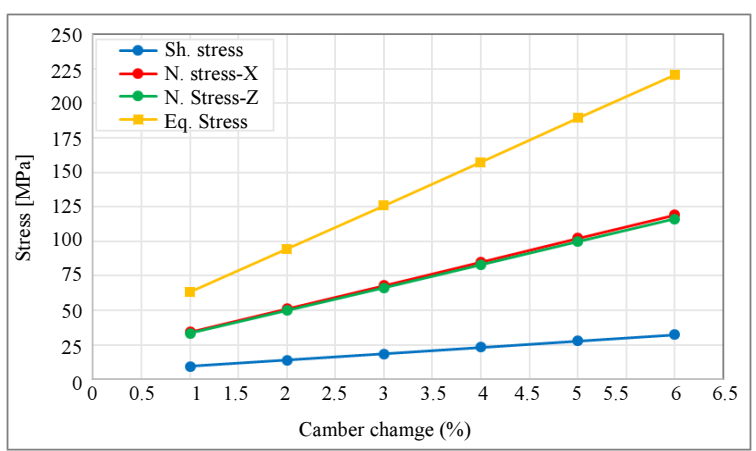

(a)

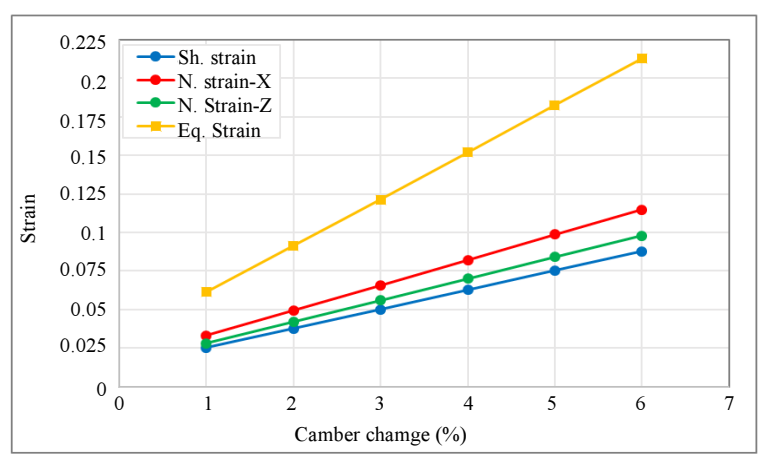

(b)

Fig. 7: (a) Camber rate vs. stress in 2D plate model and (b) camber rate vs. strain in 2D plate model

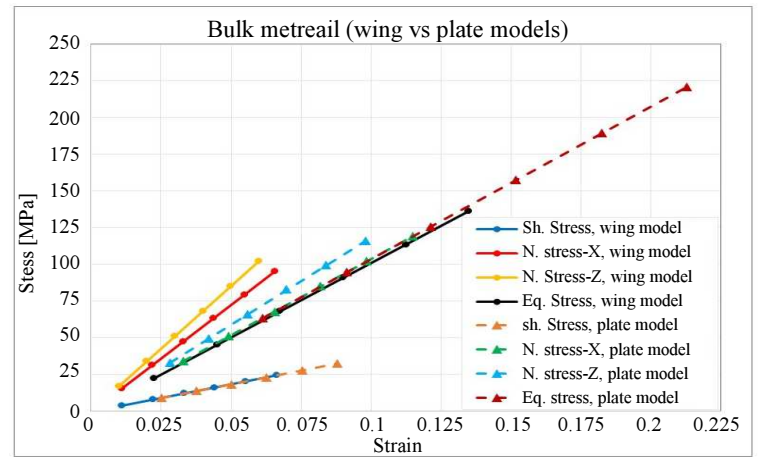

(a)

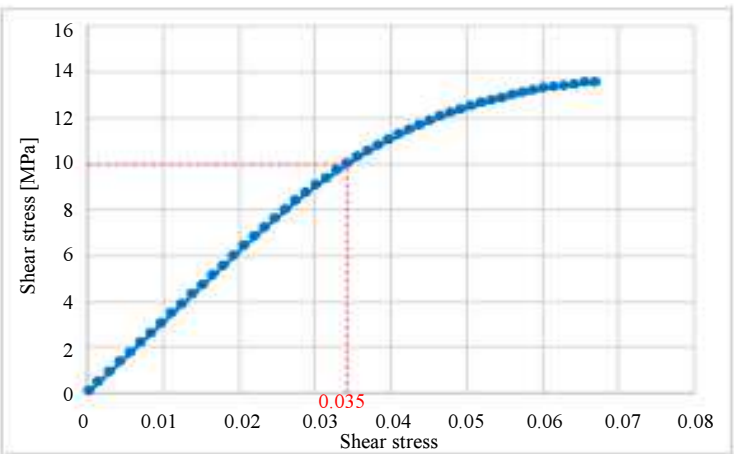

(b)

Fig. 8: Stress/strain curve of 2D-plate model versus real wing model

\section{Honeycomb Lattice Structure}

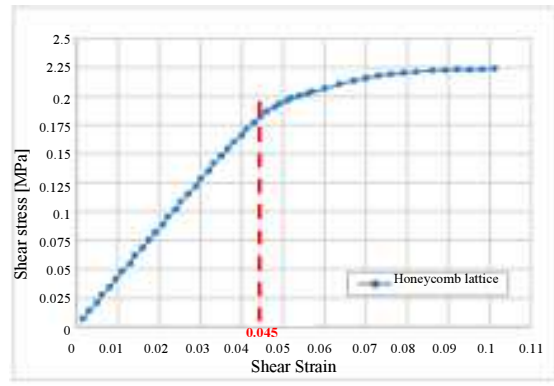

(a)
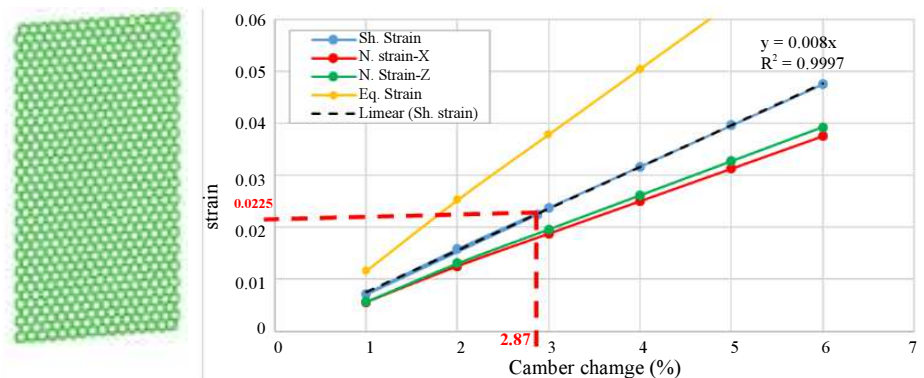

(b)

Fig. 9: (a) in-plane shear stress/strain curve for Honeycomb lattice and (b) percentage of camber change vs. corresponding strain

\section{Auxetic Lattice Structure}

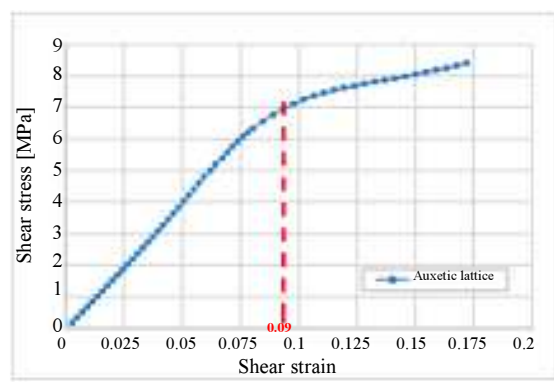

(a)
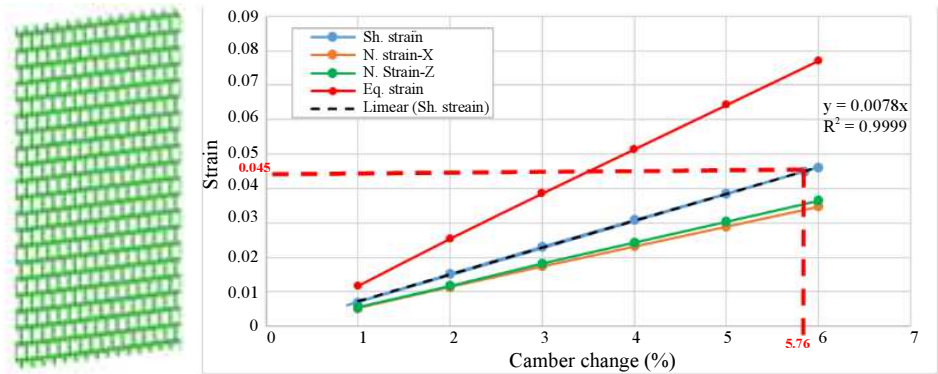

(b)

Fig. 10: (a) in-plane shear stress/strain curve for Auxetic lattice and (b) percentage of camber change vs. corresponding strain 


\section{Chiral Lattice Structure}

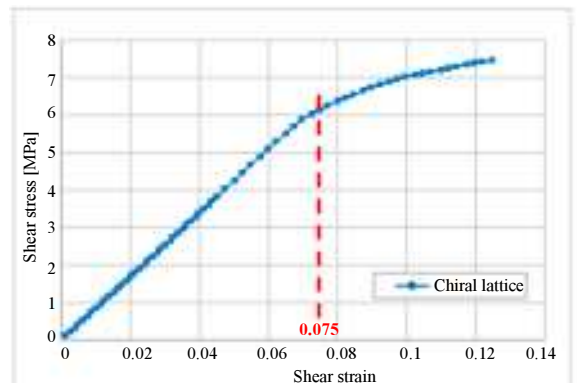

(a)
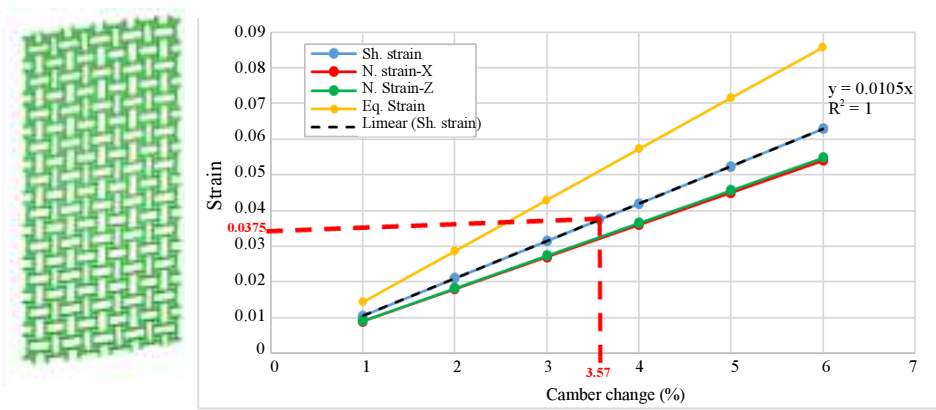

(b)

Fig. 11: (a) In-plane shear stress/strain curve for chiral lattice and (b) percentage of camber change vs. corresponding strain

\section{Zero-Poisson Ratio Lattice}

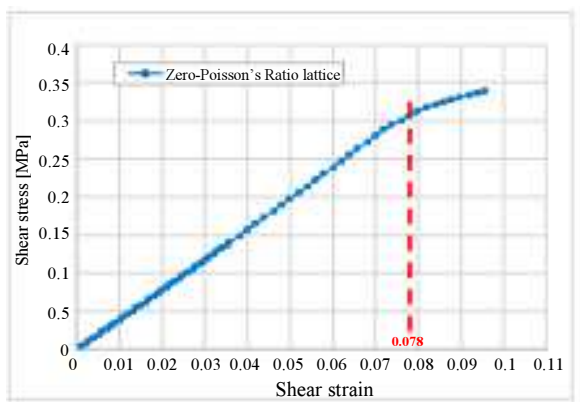

(a)
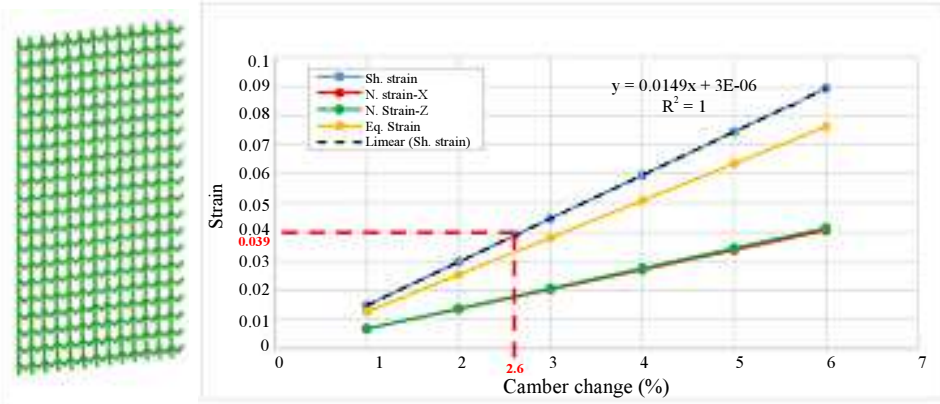

(b)

Fig. 12: (a) In-plane shear stress/strain curve for zero-poisson ratio lattice and (b) percentage of camber change vs. corresponding strain

\section{Square Lattice}

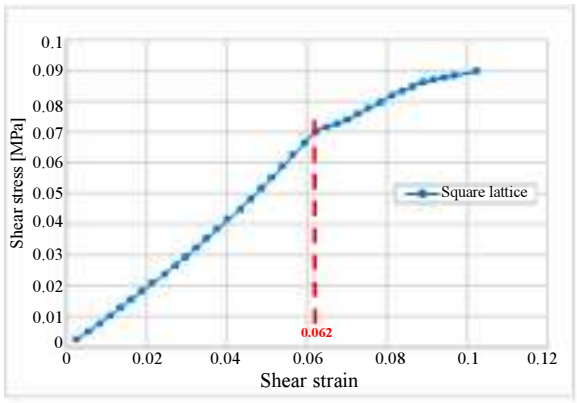

(a)
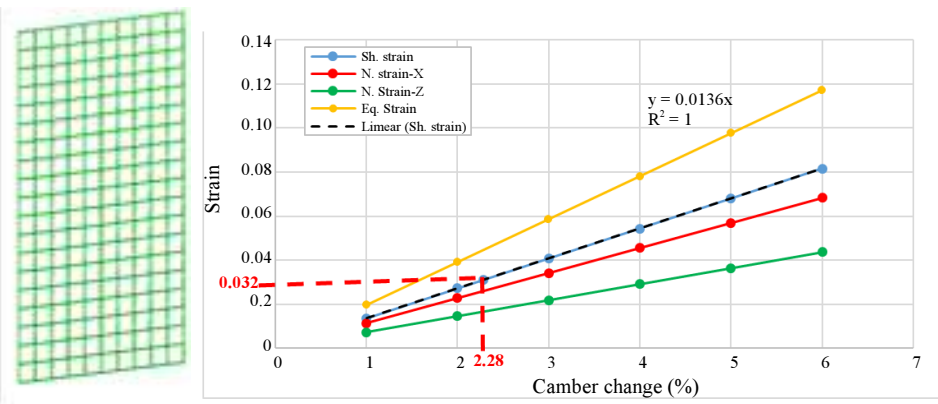

(b)

Fig. 13: (a) In-plane shear stress/strain curve for Square lattice and (b) percentage of camber change vs. corresponding strain.

Table 3: Summary of 5 different lattice structure's 2D shear stress/strain and matching camber rate

\begin{tabular}{lllll}
\hline Lattice structure & $\begin{array}{l}\text { Stress at } \\
\text { deformation }\end{array}$ & $\begin{array}{l}\text { Strain at } \\
\text { deformation }\end{array}$ & $\begin{array}{l}\text { Desired strain with } \\
\text { safety factor 2 }\end{array}$ & $\begin{array}{l}\text { Matching camber } \\
\text { rate with safety factor } \\
2 \text { of deformation }\end{array}$ \\
\hline Honeycomb & $1.8 \mathrm{MPa}$ & 0.045 & 0.0225 & $2.87 \%$ \\
Auxetic & $6.9 \mathrm{MPa}$ & 0.09 & 0.045 & $5.76 \%$ \\
Chiral & $6.1 \mathrm{MPa}$ & 0.075 & 0.0375 & $3.57 \%$ \\
Zero-Poisson & $0.31 \mathrm{MPa}$ & 0.078 & 0.039 & $2.6 \%$ \\
Square & $0.7 \mathrm{MPa}$ & 0.064 & 0.032 & $2.28 \%$ \\
\hline
\end{tabular}




\section{Summary}

The numerical analysis of sample lattice structures' results shown in Fig. 8-13 is tabulsted. As indicated in Table 3. 5 different lattice structures were studied for stress/strain. Each one graphs starting point of plastic deformation e.g) Auxetic lattice structure start the plastic deformation at $6.9 \mathrm{MPa}$ and its corresponding strain is 0.09. In the perspective of designing advanced structures, we consider safety factor of 2 for practical implementation of lattice structure for skin of camber morphing wing up to $6 \%$ rate. The column in the table, desired strain and matching camber rate show $1 / 2$ of strain at plastic deformation and corresponding camber rate of the lattice. In the example of Auxetic lattice structure shown in Fig. 10, 0.045 strain is desired considering safety factor 2 in 0.09 strain and $6.9 \mathrm{MPa}$ stress level at plastic deformation. At that moment, the matching camber rate is $5.76 \%$ which is a bit less than maximum camber range, $6 \%$. This analysis summarizes that none of lattice examples satisfies $6 \%$ camber change rate in structural analysis which naturally requires parametric studies for optimization in the future. 5.76\% of Auxetic lattice is closest to $6 \%$; however, its corresponding stress is highest at $6.9 \mathrm{MPa}$. Moreover, its strain level is 0.09 at highest rate among all.

\section{Results}

Skin is the most vulnerable and sensitive structure to aerodynamics in flight. Conventional fixed wing aircraft normally uses aluminum skin in their wings of 1-2 mm thickness to endure aerodynamic effects including gust and sometimes unexpected loadings. Furthermore, skin structure or material selection for skin simply plays a role of wrapper around the wing to be robust enough to minimally deform (another $1-2 \mathrm{~mm}$ ) according to external loadings. However, when morphing or active geometry/shape changes in wings are considered, not only structural aspects of morphing and their mechanism newly appear but also the design of skin and material becomes an important problem accordingly. In the process of advanced skin of camber morphing wing aircraft, we propose the advantage of lattice structure and their analysis. First, actual scale 3D wing model was employed to measure stress/strain while morphing up to $6 \%$ camber change. Then we verified that $2 \mathrm{D}$ plate model corresponds to it for parametric studies for futuristic optimization and modification. It is concluded that $3 \mathrm{D}$ and $2 \mathrm{D}$ models are very alike in their behaviors, particularly in-plane shear stress/strain are almost identical. This impose 2D design studies are sufficient to represent actual 3D wing model in design optimization. Aa a base structure, 5 different lattice structures were selected and studied. None of them satisfies design criteria considering safety factor 2 although Auxetic lattice structure scored high in camber rate of $5.76 \%$ which we believe to be improved through optimization process in the future.

\section{Dicsussion}

This work guides further studies on aerodynamic loadings in vertical or out-of-plane direction as well as structural loadings while morphing. Authors plan to further investigate various flight modes including takeoff, landing, and turning. This upcoming investigation will complete the envelope stuides of relation between aerodynamic loading and structural loading condition while camber morphing. Furthermore, $3 \mathrm{~d}$ additive manufacturing perspectives of designed skin structure for camber morphing wing will be furthere implemented to complete the study while this study focuses on the fundamental investigation of numerical studies for the $3 \mathrm{~d}$ manufacturing of skin structure.

\section{Acknowledgments}

This material is based upon work supported by the DOE (Department of Energy) Research under award number DE-NA0003867 and previously advised by AFRL RQ (Air Force Research Laboratory Aerospace Directorate).

\section{Author's Contributions}

Bashir Alsaidi: Analysis, Modeling, Numerical analysis and verification, Writing and Coding.

W. Yeol Joe: Funding, Analysis, Concept establishment, Writing, Proof-reading and Main conceptualization.

Muhammad Akbar: Advising, Modeling, Analysis and Proof reading.

\section{Ethics}

This article is original and contains unpublished material. The corresponding author confirms that all of the other authors have read and approved the manuscript and no ethical issues involved.

\section{References}

Ajaj, R.M., M.I. Friswell and F.E.I. Saavedra, 2014. An integrated conceptual design study using span morphing technology. J. Intell. Mater. Syst. Struct., 25: 989-1008.

Akbar, B.M., S. La, W.Y. Joe, H. You and S. Kim et al., 2018. Modeling and Stress Analysis of Composite Skin Structure for Camber Morphing Wing. Proceedings of the Multidisciplinary Analysis and Optimization Conference, June 25-29, AIAA, GA, 2018-2934. DOI: $10.2514 / 6.2018-2934$ 
Alsulami, A., M. Akbar and W.Y. Joe, 2017. A comparative study: Aerodynamics of morphed airfoils using CFD techniques and analytical tools. Proceedings of the Advances in Aerospace Technology, Nov. 3-9, FL, USA, pp: 722769.

DOI: 10.1115/IMECE2017-72269

ANSYS Fluent Theory Guide, 2016, Release 17.2. ANSYS Inc, USA.

Barbarino, S., O. Bilgen, R.M. Ajaj, M.I. Friswell and D.J. Inman, 2011. A review of morphing aircraft. J. Intell. Mater. Syst. Struct., 22: 823-877.

Beaverstock, C., R. Ajaj, M. Friswell, R. de Breuker and N. Wetter, 2013. Optimizing mission performance for a morphing mav. Proceedings of the Ankara International Aerospace Conference, Sept. 1-2, Turkey, pp: 11-13.

Bilgen, O., K. Kochersberger, E. Diggs, A. Kurdila and D. Inman, 2007. Morphing wing aerodynamic control via macro-fiber-composite actuators in an unmanned aircraft. Proceedings of the AIAA Aerospace Conference and Exhibit, pp: 2741-2741.

Blondeau, J. and D. Pines, 2007. Design and testing of a pneumatic telescopic wing for unmanned aerial vehicles. J. Aircr., 44: 1088-1099.

Blondeau, J., J. Richeson and D.J. Pines, 2003. Design, development and testing of a morphing aspect ratio wing using an inflatable telescopic spar. Proceedings of the 44th AIAA/ASME Structures, Structural Dynamics and Materials Conference, Apr. 3, Norfolk, Virginia, pp: 7-10.

Chekkal, I., R. Cheung, C. Wales, J.E. Cooper and N. Allen et al., 2014. Design of a morphing wing tip. Proceedings of the 22nd AIAA/ASME/AHS Adaptive Structures Conference AIAA SciTech, Jan. 1, National Harbor, MD, USA, 13-17.

Jenett, B., S. Calisch, D. Cellucci, N. Cramer and N. Gershenfeld et al., 2017. Digital morphing wing: Active wing shaping concept using composite latticebased cellular structures. Soft Roboti., 4: 33-48.

La, S., B. Alsaidi, W.Y. Joe and M. Akbar, 2018. Surveys on skin design for morphing wing aircraft: Status and challenges. Proceedings of the AIAA SciTech Forum, (ACF' 18), Florida, USA, pp: 310-315.
Marques, M., P. Gamboa and E. Andrade, 2009. Design of a variable camber flap for minimum drag and improved energy efficiency. Proceedings of the 50th AIAA/ASME Structures, Structural Dynamics, and Materials Conferences, May 4-7, Palm Springs, CA, USA, pp: 4-7.

Mestrinho, J., P. Gamboa and P. Santos, 2011. Design optimization of a variable-span morphing wing for a small uav. Proceedings of the 52nd AIAA/ASME/ASCE/AHS/ASC Structures, Structural Dynamics and Materials Conference, Jun. 14, Denver, CO, USA, pp: 4-7. DOI: $10.2514 / 6.2011-2025$

Oliviu, S.G., A. Koreanschi, R.M. Botez, M. Mamou and Y. Mebarki, 2016. Analysis of the aerodynamic performance of a morphing wing-tip demonstrator using a novel nonlinear vortex lattice method. Proceedings of the American Institute of Aeronautics and Astronautics AIAA Aviation Conference, Jun. 13-17, Washington, DC, USA, pp: 4036-4036. DOI: 10.2514/6.2016-4036

Santer, M. and S. Pellegrino, 2019. Topological optimization of compliant adaptive wing structure. AIAA J., 47: 523-534.

Smith, D.D., R.M. Ajaj, A.T. Isikveren and M.I. Friswell, 2012. Multiobjective optimization for the multi-phase design of active polymorphing wings. J. Aircr. 49: 1153-1160. DOI: 10.2514/1.C031499

Sofla, A.Y.N., S.A. Meguid, K.T. Tan and W.K. Yeo, 2009. Shape morphing wing design: Current status and challenges. Mater. Des., 31: 1284-1292.

Vigliotti, A. and D. Pasini, 2015. Analysis and design of lattice materials for large cord and curvature variations in skin panels of morphing wings. Smart Mater. Structures, 24: 037006-037006.

Woods, B.K.S. and M.I. Friswell, 2013. Structural analysis of the fish bone active camber concept. Proceedings of the AIDAA 22th Conference, Sept. 9-12.

Woods, B.K.S. and M.I. Friswell, 2014. Structural characterization of the fish bone active camber morphing airfoil. Proceedings of the 22nd AIAA/ASME/AHS Adaptive Structures Conference, Jan. 13-17, National Harbor, MD, USA, pp: 13-17. DOI: $10.2514 / 6.2014-1122$ 